

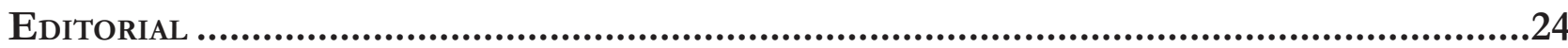

O Direito na fronteira da razão: Psicologia, neurociência e economia comportamental................... 24 Patrícia Perrone Campos Mello e Sergio Nojiri

I. NeURodireito: COGNIÇão, EMOÇÃo, JUÍZOS MORAIS E CIÊNCIA ..........................................26

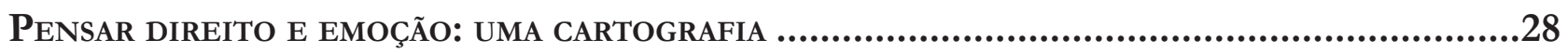

Nevita Maria Pessoa de Aquino Franca Luna

Neurodireito: o início, o fim E O MEIO

Carlos Marden e Leonardo Martins Wykrota

ENSAIO JURÍDICO SOBRE A RACIONALIDADE HUMANA: MAIORES, CAPAZES E IRRACIONAIS

André Perin Schmidt Neto e Eugênio Facchini Neto

DIVERGÊNCIAS DE PRINCÍPIO: ARGUMENTOS JURÍDICOS E MORAIS EM UM CENÁRIO DE DESACORDOS SOCIAIS

André Matos de Almeida Oliveira, Pâmela de Rezende Côrtes e Leonardo Martins Wykrota

CONSILIÊNCIA E A POSSIBILIDADE DO NEURODIREITO: DA DESCONFIANÇA À RECONCILIAÇÃO DISCIPLINAR.....

Thaís de Bessa Gontijo de Oliveira e Renato César Cardoso

MODELOS DE MORALIDADE

Molly J. Crockett

A INFELIZ BUSCA POR FELICIDADE No DiREITo

Úrsula Simões da Costa Cunha Vasconcellost, Noel Struchiner e Ivar Hannikainen

Além da liberdade: PersPeCtivas Em Nietzsche.

Lucas Costa de Oliveira

A mediaÇão de CONFlitos SOb a PERSPECTIVA do DESENVOLVIMENTO HUMANO: AS CONTRIBUIÇÕES DA PSICOLOGIA POSITIVA

Simone de Biazzi Ávila Batista da Silveira e Deise Brião Ferraz

Neuroimagiologia e aValiação de ResPonsabilidade

Nicole A. Vincent 
ANÁLISE CRÍTICA DA ORIENTAÇÃO DE CIDADÃOS COMO MÉTODO PARA OTIMIZAR DECISÕES PÚBLICAS POR MEIO DA TÉCNICA NUDGE.

Luciana Cristina Souza, Karen Tobias França Ramos e Sônia Carolina Romão Viana Perdigão

Políticas públicas e o deVer de monitoramento: “LEVANdo os Direitos A SÉrio". .252 Ana Paula de Barcellos

Nudges E POLÍticas PÚblicas: uM MECANISMO DE COMBATE AO TRABALHO EM CONDIÇÃo ANÁLOGA À DE ESCRAVO .267

Amanda Carolina Souza Silva, Débhora Renata Nunes Rodrigues e Saul Duarte Tibaldi

REDUZINDO A TRIBUTAÇÃO COGNITIVA: LIÇÕES COMPORTAMENTAIS PARA A DIMINUIÇÃO DOS EFEITOS PSICOLÓGICOS ADVERSOS DA POBREZA.............................................................288 Leandro Novais e Silva, Luiz Felipe Drummond Teixeira, Gabriel Salgueiro Soares e Otávio Augusto Andrade Santos

Políticas PÚBLICAS EM SUICÍDIO: DO PATERNALISMO CLÁSSICO AO PATERNALISMO LIBERTÁRIO E NUDGING

Davi de Paiva Costa Tangerino, Gabriel Cabral e Henrique Olive

Nudges COMO POLÍticA PÚbliCA PARA AUMENTAR O ESCASSO NÚMERO DE DOADORES DE ÓRGÃos PARA TRANSPLANTE

Roberta Marina Cioatto e Adriana de Alencar Gomes Pinheiro

Os PROGRAMAS DE INTEGRIDADE PARA CONTRATAÇÃO COM A ADMINISTRAÇÃO PÚBLICA ESTADUAL: NUDGE OU OBRIGAÇÃo LEGAL? UM OLHAR SOBRE AS DUAS PERSPECTIVAS .386

Cíntia Muniz Rebouças de Alencar Araripe e Raquel Cavalcanti Ramos Machado

Paternalismo libertário e Proteção JURídica do AMbiente: POR QUe PROTEger o AMBIENTE TAMBÉM DEVE SER PROTEGER AS LIBERDADES?

Mariana Carvalho Victor Coelho e Patryck de Araujo Ayala

Políticas PÚblicas baseadas EM EVIdÊNCIAS COMPORTAMENTAIS: REFLEXões A PARTIR do Projeto de Lei 488/2017 do Senado

Pâmela de Rezende Côrtes, André Matos de Almeida Oliveira e Fabiano Teodoro de Rezende Lara

III. ECONOMIA COMPORTAMENTAL: VIESES COGNITIVOS E POLÍTICAS PÚBLICAS .455

ECONOMIA COMPORTAMENTAL E DIREITO: A RACIONALIDADE EM MUDANÇA Marcia Carla Pereira Ribeiro e Victor Hugo Domingues

VIESES COGNITIVOS E DESENHO DE POLÍTICAS PÚBLICAS 
A neurociênCia da moralidade na tomada de DeCisões Jurídicas Complexas e No DESENHO DE POLÍTICAS PÚBLICAS

Erik Navarro Wolkart

Desvio de CARÁter ou SIMPLESMENTE HUMANO? ECONOMIA COMPORTAMENTAL APLICADA AO COMPORTAMENTO DESONESTO

Diana Orghian, Gabriel Cabral, André Pinto e Alessandra Fontana

Políticas Públicas e a ConcretizaÇão de direitos sociais: TOMAdA DE DECisão, ARQUITETURA DE ESCOLHAS E EFETIVIDADE

Ana Elizabeth Neirão Reymão e Ricardo dos Santos Caçapietra

BEHAVIORAL ECONOMICS E DIREITO DO CONSUMIDOR: NOVAS PERSPECTIVAS PARA O ENFRENTAMENTO DO SUPERENDIVIDAMENTO .568

Samir Alves Daura

A EDUCAÇÃo FORMAL PARA O CONSUMO É GARANTIA PARA UMA PRESENÇA REFLETIDA DO CONSUMIDOR NO MERCADO? UMA ANÁLISE COM BASE NA BEHAVIORAL LAW AND ECONOMICS (ECONOMIA COMPORTAMENTAL) 600

Marcia Carla Pereira Ribeiro e Edson Mitsuo Tiujo

LIBET, DETERMINISMO E CONSUMO: AS INFLUÊNCIAS DO MARKETING E A RELEVÂNCIA DA DELIBERAÇÃo CONSCIENTE NA SUPERAÇÃo CONDICIONAL DE HÁBITOS DE CONSUMO PERIGOSOS616 Émilien Vilas Boas Reis e Leonardo Cordeiro de Gusmão

CiÊNCIA DO DIREITO TRIBUTÁRIO, ECONOMIA COMPORTAMENTAL E EXTRAFISCALIDADE. .640 Hugo de Brito Machado Segundo

IV. CoMportamento JUdiCiAL: INFLUÊNCIA DE FATORES EXTRAJURÍDicos .660

FATORES METAPROCESSUAIS E SUAS INFLUÊNCIAS PARA A FORMAÇÃo DA DECISÃo JUDICIAL .662 Rogério Roberto Gonçalves de Abreu, Lúcio Grassi de Gouveia e Virgínia Colares

“A VIDA COMO ELA É": COMPORTAMENTO ESTRATÉGICO NAS CORTES Patrícia Perrone Campos Mello

A COMPOSIÇÃo do ÓRGão COLEGIAdo E SEUS EFEITOS NA TOMADA DE DECISÃo .720 André Garcia Leão Reis Valadares

Das 11 ilhas ao centro do arquipélago: os superpoderes do Presidente do STF DURANTE O RECESSO JUDICIAL E FÉRIAS .741 José Mário Wanderley Gomes Neto e Flávia Danielle Santiago Lima 
RAZÃo, EMOÇÃo E DELIBERAÇÃO: AS ADEQUAÇÕES REgIMENTAIS do SUPERIOR TribUNAL DE JUSTIÇA PARA A FORMAÇÃo DE PRECEDENTES EFICAZES

Peter Panutto e Lana Olivi Chaim

Heurística de ancoragem e fiXaÇÃo de danos morais em JUizados especiais Cíveis no Rio DE JANEIRO: UMA NOVA ANÁLISE 778

Fernando Leal e Leandro Molhano Ribeiro

LA PROTECCIÓN DE LOS DERECHOS POLÍTICOS FRENTE A LAS FUNCIONES DISCIPLINARIAS DE LAS AUTORIDADES ADMINISTRATIVAS: SUBSIDIARIEDAD Y DEFERENCIA EN EL SISTEMA INTERAMERICANO DE DERECHOS HUMANOS Jorge Ernesto Roa Roa

V. A influênCia do gÊNERo no PROCESSO DECisório JUdiCial

Como os Juízes decidem os Casos de estupro? ANALISANDo SENTENÇAS SOb A PERSPECTIVA DE VIESES E ESTEREÓTIPOS DE GÊNERO 826 Gabriela Perissinotto de Almeida e Sérgio Nojiri

GÊNERO E COMPORTAMENTO JUDICIAL NO SUPREMO TRIBUNAL FEDERAL: OS MINISTROS CONFIAM MENOS EM RELATORAS MULHERES?

Juliana Cesario Alvim Gomes, Rafaela Nogueira e Diego Werneck Arguelhes

Hércules, Hermes e a Pequena Sereia: uma reflexão sobre estereótipos de gênero, SUBPRESENTAÇÃo DAS MULHERES NOS TRIBUNAIS E (I)LEGITIMIDADE DEMOCRÁTICA DO PODER JUDICIÁRIO. .878 Jane Reis Gonçalves Pereira e Renan Medeiros de Oliveira

Prisão Cautelar de gestantes: análise do Fundamento filosófico da decisão do Habeas CoRpus N. 143.641 912

Artur César Souza e Giovania Tatibana de Souza

VI. Neurodireito APlicado ao direito E Ao Processo PENAL....................................926

CÉREbros QUe PUNEM: UMA REVISÃo CRÍTICA DA NEURoCIÊNCIA DA PUNIÇÃo .....................928 Ricardo de Lins e Horta

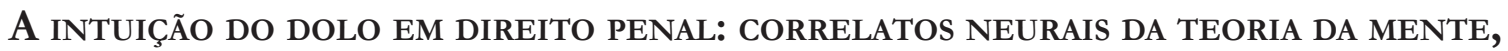
RACIOCÍNIO INDUTIVO E A GARANTIA DA CONVICÇÃO JUSTIFICADA. .946 Thiago Dias de Matos Diniz e Renato César Cardoso

As COMUNIDADES EPISTÊMICAS PENAIS E A PRODUÇÃo LEGISLATIVA EM MATÉRIA CRIMINAL..... 961 Stéphane Enguéléguélé 
DELINQUÊNCIA JUVENIL: RELAÇÕES ENTRE DESENVOLVIMENTO, FUNÇÕES EXECUTIVAS E COMPORTAMENTO SOCIAL NA ADOLESCÊNCIA .

André Vilela Komatsu, Rafaelle CS Costa e Marina Rezende Bazon

Límites TEMPORALES A LAS PENAS PRIVATIVAS DE LIBERTAD ATENDIENDO AL DESARROLLO PSICOSOCIAL.

Silvio Cuneo Nash

NEURolaw E AS PERSPECTIVAS PARA UMA ANÁLISE OBJETIVA DO COMPORTAMENTO SUGESTIONADO: REPERCUSSÃO DAS FALSAS MEMÓRIAS NA ESFERA PENAL

Mariana Dionísio de Andrade, Marina Andrade Cartaxo e Rafael Gonçalves Mota

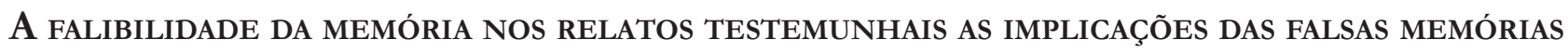
NO CONTEXTO DOS CRIMES CONTRA A DIGNIDADE SEXUAL

Caroline Navas Viana

A (IR)REPETIBILIDADE dA PROVA PENAL DEPENDENTE DA MEMÓRIA: UMA DisCUSSÃo COM BASE NA PSICOLOGIA DO TESTEMUNHO. 1058

William Weber Cecconello, Gustavo Noronha de Avila e Lilian Milnitsky Stein 


\section{Políticas públicas e o dever de monitoramento: "levando os direitos a sério"*}

\section{Public policies rights and monitoring: "taking rights seriously"}

Ana Paula de Barcellos**

\section{Resumo}

o objetivo deste trabalho consiste em demonstrar que o efetivo respeito, proteção e promoção dos direitos fundamentais depende sobretudo dos resultados concretos de políticas públicas existentes acerca desses direitos, e não apenas da existência de normas ou mesmo de decisões judiciais sobre o tema, de tal modo que o monitoramento e avaliação dos resultados dessas políticas, de forma desagregada, a fim de se captar a desigualdade tanto da realidade quanto da execução da própria política pública, torna-se um tema profundamente relevante para o direito constitucional. Nesse contexto, com base em pesquisa empírica e doutrinária, e com fundamento no método dedutivo, o trabalho passa a propor, em sua segunda parte, uma estrutura básica para o monitoramento das políticas públicas sob a perspectiva da realização dos direitos fundamentais. A terceira parte do trabalho procura sustentar que a existência de sistemas de monitoramento no contexto de políticas públicas de direitos fundamentais deve ser considerado um dever jurídico-constitucional.

Palavras-chave: Políticas públicas. Direitos fundamentais. Monitoramento. Avaliação.

\section{Abstract}

the paper seeks to show that real respect, protection and promotion of fundamental rights depend primarily on the concrete results of existing public policies focused on these rights, not only on the existence of norms or even judicial decisions on the subject. Therefore, the permanent monitoring and evaluation of public policies' results, in a disaggregated way, in order to capture the inequality of both reality and the implementation of public policy itself, is a deeply constitucional matter. In this context, based on empirical and doctrinal research, and the method of deductive approach, the second part of the paper proposes a basic structure for the monitoring of public policies from a fundamental rights perspective. In the third part, the paper argues that the existence of monitoring systems in the context of public policies focused on the promotion of fundamental rights should be considered a constitutional duty.

Key words: Public policies. Fundamental rights. Monitoring. Evaluation.

\footnotetext{
** Professora Titular de Direito Constitucional da Faculdade de Direito da UERJ. PósDoutora - Harvard. Doutora e Mestre - UERJ. Advogada e parecerista. Email: abarcellos@ bfbm.com.br

ber.com.br
}

Recebido em 30/05/2018

Aprovado em 09/07/2018 


\section{INTRODUÇÃO: NORMAS E DECISÕES JUDICIAIS E SEUS LIMITES: DIREITOS FUNDAMENTAIS E POLÍTICAS PÚBLICAS}

O tema dos direitos humanos, no plano internacional, e dos direitos fundamentais, no plano interno, tem sido central e, com razão, nos debates do Direito Constitucional brasileiro nas últimas décadas. A Constituição de 1988 veiculou o compromisso do novo Estado brasileiro, reorganizado naquele momento, com a promoção dos direitos fundamentais, direitos que ela prevê de forma mais ou menos analítica. Também, no plano internacional, desde a Declaração Universal dos Direitos Humanos, em 1948, diversos outros documentos foram celebrados tratando do respeito, proteção e promoção de direitos específicos ou relacionados a grupos humanos em particular.

No Brasil, a respeito das críticas em geral dirigidas ao Poder Legislativo, é certo que houve, nas últimas décadas, uma prolífica produção acerca dos mais variados direitos. O exemplo da saúde é emblemático, mas não é único. Um visitante estrangeiro sem qualquer conhecimento adicional sobre o país que tentasse avaliar a situação dos direitos humanos a partir, exclusivamente, das normas em vigor chegaria a conclusões distantes da realidade.

Considerando-se o exemplo da saúde, cerca de dois anos após a promulgação da Constituição de 1988, foi editada a Lei n 8.080/90, que organizou a estrutura básica do Sistema Único de Saúde, previsto constitucionalmente. Várias alterações foram introduzidas nessa lei ao longo do tempo para adaptar o sistema a novas necessidades e realidades, em geral sempre no sentido de ampliar os serviços que em tese deveriam ser fornecidos à população. A Lei no 12.401/11, por exemplo, alterou a Lei Geral do SUS, dentre outras previsões, para incluir, nas atividades a serem desenvolvidas pelo sistema, os serviços de atendimentos ou atenção domiciliar.

No plano infralegal, normas são constantemente expedidas dispondo sobre os serviços prestados pelo SUS, o relacionamento entre os entes federativos e com os parceiros privados, dentre muitos outros temas. A lista de medicamentos a serem fornecidos pelo SUS divulgada em 2017 (Relação Nacional de Medicamentos Essenciais - RENAME ${ }^{1}$ ), por exemplo, conta com 869 itens, contra 842 da edição de $2014^{2}$. Nada obstante, não é incomum que medicamentos tradicionalmente incluídos nessa listagem, como os usados para atendimentos de emergência, para controle de diabetes, pressão alta, doenças coronarianas dentre outros, estejam em falta em vários pontos do país ${ }^{3}$.

Em alguma medida, é natural que haja um descompasso entre realidade e normas: o direito existe afinal para transformar a realidade; para que tudo permaneça como é, não haveria necessidade de editar norma alguma. De outra parte, porém, é também certo que o direito não é portador de palavras mágicas capazes de, por sua mera enunciação, transformar o mundo real. A transformação efetiva da realidade na linha do que consta das normas é em geral o objetivo da norma, mas, como regra, não se segue a ela de forma automática ou imediata.

Paralelamente à edição de normas pelo Legislativo e Executivo, a doutrina jurídica brasileira dedicou-se, nas últimas décadas, a desenvolver uma dogmática voltada para a expansão da eficácia jurídica e da efetivi-

1 BRASIL. Ministério da Saúde. Relação nacional de medicamentos essenciais: 2017. Disponível em: < http://bvsms.saude.gov.br/bvs/ publicacoes/relacao_nacional_medicamentos_rename_2017.pdf>.

2 BRASIL. Ministério da Saúde. Relação nacional de medicamentos essenciais: 2017. Disponível em: <http://bvsms.saude.gov.br/bvs/ publicacoes/relacao_nacional_medicamentos_rename_2017.pdf>.

3 <http://www.gazetadopovo.com.br/vida-e-cidadania/dois-em-cada-dez-medicamentos-estao-em-falta-nos-postos-de-saudede-curitiba-6rird1cpwq4oni5dmn2upvewr>.; $\quad<$ https://www.viagora.com.br/noticias/parnaiba-vive-problemas-com-falta-demedicamentos-em-postos-de-saude-68091.html ; https://g1.globo.com/ac/acre/noticia/fiscalizacao-detecta-falta-de-medicamento-e-baixo-efetivo-de-profissionais-em-hospital-de-rio-branco.ghtml>; https://www.msemfoco.com.br/cidades/dourados/ idenor-cobra-a-prefeitura-por-falta-de-medicamentos-em-postos-de-saude/177625/>; <https://g1.globo.com/rj/rio-de-janeiro/ noticia/doentes-cronicos-e-transplantados-estao-sem-medicamentos-na-farmacia-do-estado-do-rj.ghtml> (acesso de todos em: 28 abr. 2018). 
dade da Constituição como um todo e dos direitos fundamentais de forma específica. A jurisprudência tem seguido na mesma linha, em todos os ramos do Poder Judiciário e graus de jurisdição, e sequer há necessidade de enumerar exemplos de decisões nesse sentido. O Supremo Tribunal Federal, em múltiplas ocasiões, tem destacado a centralidade dos direitos fundamentais e da dignidade humana no sistema jurídico-constitucional brasileiro.

Todos esses esforços — normativos, doutrinários e jurisprudenciais — pretendem, em última análise, garantir, proteger e promover os direitos fundamentais. E parece certo que eles são efetivamente importantes para a realização dos direitos nos Estados contemporâneos, embora não sejam suficientes. Nada obstante, é preciso reconhecer que a edição de normas, a produção doutrinária e mesmo a prolação de decisões judiciais não garantem, por si, a realização de direitos. $O$ fato de existirem múltiplas normas disciplinando o direito à saúde, doutrina tratando de sua fundamentalidade e eficácia, e mesmo decisões judiciais impondo obrigações nesse sentido, nada disso significa, a rigor, que as normas e as decisões estejam sendo efetivamente executadas e que as pessoas — todas as pessoas — estejam recebendo aquilo que as normas prometem.

O ponto é particularmente importante, pois, durante algum tempo, se alimentou a esperança de que, embora as normas por si não fossem capazes de alterar a realidade, o Judiciário seria capaz de garantir, de forma geral, a efetividade dos direitos fundamentais: mas essa esperança não era realista desde sua origem. Nas últimas décadas, multiplicaram-se decisões judiciais, ao redor do mundo e no Brasil, com o objetivo de promover a realização de direitos fundamentais. Os exemplos envolvendo direitos sociais são provavelmente os mais emblemáticos, mas não são únicos: demandas envolvendo direito à água, à alimentação, a prestações de saúde, à habitação, a saneamento básico etc.

Em primeiro lugar, por mais numerosas que sejam as ações judiciais, elas representam uma parcela pequena da realidade: a maioria absoluta da população brasileira passará toda a sua vida e jamais será beneficiária de uma decisão judicial em matéria de saúde ou educação. Por exemplo, por mais que a judicialização da saúde venha crescendo ${ }^{4}$, essas demandas continuam sendo pontuais no universo de usuários exclusivos do SUS, composto por cerca de $78 \%$ da população brasileira: quase 162 milhões de pessoas ${ }^{5}$. O que a maior parte dessas pessoas fruirá ou não, no que diz respeito a esses direitos, será aquilo que as políticas públicas delineadas e levadas a cabo pelos Poderes Executivo e Legislativo realizarem. E, em geral, essa maioria é a menos privilegiada no contexto da sociedade ${ }^{6}$.

Em segundo lugar, os problemas envolvendo a efetiva execução, no mundo dos fatos, do que tenha sido determinado pelo Judiciário, é um tema que tem suscitado amplo debate entre acadêmicos e ativistas ao redor do mundo. Afinal, em si mesmas, as decisões judiciais também não têm o condão de modificar a realidade: elas são apenas palavras em folhas de papel ou meios digitais. A conclusão preliminar a que já se chegou sobre o ponto, não apenas no Brasil, mas também em outros países, é a de que as decisões judiciais são executadas de forma razoável quando se trate de bens privados postulados em demandas individuais, como, e.g., a entrega de medicamentos para determinado indivíduo.

Entretanto, quando se cuida de ações coletivas e/ou de demandas que envolvem bens públicos, como a alteração, correção ou implantação de uma política pública, a execução das decisões judiciais pode demorar décadas ou eventualmente nunca acontecer ${ }^{7}$. Isso sem ingressar na discussão acerca de quem afinal acessa

4 <http://portalarquivos.saude.gov.br/images/pdf/2014/maio/29/Panorama-da-judicializa----o---2012---modificado-em-junho-de-2013.pdf $>$.

5 <http://www.ans.gov.br/perfil-do-setor/dados-gerais $>$.

6 BILCHITZ. Poverty and fundamental rights. New York: Oxford University Press, 2007.;GARGARELLA, R.; DOMINGO, P.; ROUX, T. (Ed.). Courts and social transformation in new democracies: an institutional voice for the poor?. Aldershot/Burlington: Ashgate, 2006.

7 V. discutindo a questão os textos reunidos na coletânea de GAURI; BRINKS (Ed.). Courting social justice: judicial enforcement of social and economic rights in the developing world. Cambridge: Cambridge University Press, 2008. Veja-se para ações tratando de saneamento no Brasil, BARCELLOS, Ana Paula de. Sanitation rights, public law litigation and inequality: a case study from Brazil. Health and Human Rights, v. 16, n. 2, p. 35-46, 2014. 
o Poder Judiciário para postular demandas em matéria de saúde, embora já se saiba que, raramente, são os mais excluídos da sociedade.

Não se trata de minimizar os vários papéis que as decisões judiciais têm e podem ter no tema dos direitos, mas apenas de constatar que é ilusório imaginar que possa caber ao Judiciário a função de garantir o respeito, proteção ou promoção dos direitos fundamentais em caráter geral. A edição de uma lei criando uma política pública de promoção de determinado direito será um ponto de partida: indispensável, sem dúvida, mas apenas um ponto de partida. Em boa medida o mesmo acontece com decisões judiciais mais complexas, que pretendem interferir com políticas públicas de forma coletiva. A transformação da realidade não se seguirá magicamente à expedição da norma e sequer a execução da própria lei e da política por ela delineada são automáticas.

Haverá, no mínimo, dois grandes processos no percurso que pode levar uma norma a produzir efetivamente a proteção, a promoção ou o respeito de direitos fundamentais no mundo real. Em primeiro lugar, a política pública prevista na norma — isto é: seu conteúdo, as medidas por ela delineadas — precisará de fato ser implementada. Esse primeiro momento dependerá de uma série de providências como, e.g., a criação de estruturas administrativas, a contínua alocação orçamentária, a contratação de pessoal e infraestrutura suficientes para atender a todos os públicos alvo da política, a compra de produtos e a contratação de serviços, a produção de relatórios, pesquisas, o monitoramento etc.

Não é incomum, porém, que uma lei seja aprovada prevendo determinada política e não seja regulamentada. Ou que anos se passem sem que haja previsão orçamentária para a execução da lei, ou que haja previsão orçamentária, mas ela não seja realmente executada. É possível ainda que a política seja implementada apenas em determinadas regiões (do país, do Estado, da cidade) ou apenas em benefício de determinados públicos, ou que os recursos (financeiros, humanos, técnicos) não sejam suficientes para sua execução, dentre outras possibilidades. Enfim, um sem número de questões podem surgir, e efetivamente surgem entre a norma e sua execução.

Dois exemplos ilustram o ponto. A lei que prevê a obrigatoriedade de que vias e espaços públicos sejam adaptados para garantir a acessibilidade de pessoas com mobilidade reduzida é de 2000 (Lei n 10.098), mas até hoje não foi integralmente executada. Além disso, é muito provável que, na maior parte das cidades, os percentuais de sua execução não sejam os mesmos em todos os bairros e que os bairros considerados mais nobres, onde mora a população de maior renda, tenham melhores percentuais de execução da política pública do que as regiões mais carentes da cidade: trata-se de uma tendência observada em várias pesquisas que examinam políticas públicas de caráter geral e sua execução ao longo do tempo ${ }^{8}$.

Em 2015, o IPEA divulgou uma avaliação nacional feita sobre os resultados e a efetividade da Lei Maria da Penha, promulgada em 2006. O estudo revela o impacto positivo da lei de uma forma geral, na média nacional, no que diz respeito à redução proporcional de homicídios contra mulheres. Todavia, o estudo destaca, também, que a execução das políticas previstas pela lei varia bastante regionalmente, e, talvez por isso mesmo, também o impacto esperado da lei não é uniforme, oscilando em função da região examinada.

Uma vez que a norma esteja sendo implementada — e, portanto, esse primeiro aspecto do percurso norma-realidade esteja em andamento - , será preciso verificar se os resultados que dela se esperava estão se produzindo realmente, tanto em caráter geral, quanto, desagregando essa informação, tendo em conta as diferentes regiões e os diferentes grupos humanos no país. Esse processo é um pouco mais complexo, em primeiro lugar, porque, nem sempre, a política pública tinha/tem resultados ou metas claramente definidas.

8 VICTORA, Cesar G. et al. Explaining trends in inequities: evidence from Brazilian child health studies. Lancet, v. 356, p. 1093-1098, 2000; Human Rights Watch. World report. 2012. Disponível em: < https://www.hrw.org/sites/default/files/world_report_download/wr2012.pdf>. Os dois trabalhos ilustram a chamada "inverse equity hypothesis" segundo a qual as populações mais favorecidas tendem a se beneficiar primeiro das políticas públicas gerais, aumentando ainda mais a desigualdade em um primeiro momento.

9 <http://www.ipea.gov.br/atlasviolencia/artigo/22/avaliando-a-efetividade-da-lei-maria-da-penha->. 
E, em segundo lugar, porque muitas vezes não há monitoramento acerca dos resultados que a política pública está ou não efetivamente produzindo e, portanto, não há informação sobre o assunto. Ainda um exemplo ilustra a questão.

Em 2007, o Ministério da Educação criou o programa "Mais Educação" que consistia, basicamente, em ampliar em cerca de 3 h diárias a jornada escolar de estudantes do ensino fundamental nas redes públicas estaduais e municipais a fim de ampliar as oportunidades de aprendizagem. O programa procurou focar em escolas de baixo IDEB e marcadas por situações de vulnerabilidade social. Naturalmente que o resultado pretendido seria a melhoria da aprendizagem desses estudantes. Em 2015 foi divulgado pelo Ministério da Educação estudo realizado pela Fundação Itaú Social e pelo Banco Mundial acerca dos resultados do programa.

Talvez, de forma surpreendente, o que se apurou foi que, até 2011,

não são encontrados resultados de melhoria no desempenho médio dos alunos na Prova Brasil, nem na taxa de abandono, quando comparamos escolas que tiveram o programa com outras sem ele, mas com características similares. ${ }^{10}$

Ou seja: a despeito de a política "Mais Educação" estar sendo executada, e apesar de suas melhores intenções, os resultados pretendidos não estavam se produzindo. Fenômeno similar se observa de forma mais geral, a rigor, no sistema educacional brasileiro. Embora se tenha praticamente obtido a universalização das matrículas para crianças e adolescentes — o que deve ser comemorado - , para um percentual alarmante de estudantes a escolarização não é garantia de alfabetização funcional ou de qualificação para o trabalho ${ }^{11}$, apesar do que dispõe o art. 205 da Constituição ${ }^{12}$.

Esses comentários iniciais revelam as limitações das normas e da jurisdição no que diz respeito à promoção dos direitos fundamentais, e conduzem ao tema do monitoramento de políticas públicas, sobre o que se vai tratar na segunda e na terceira partes deste texto. Na verdade, o que se pretende sustentar é que o monitoramento de políticas públicas em matéria de direitos fundamentais, e dos seus resultados em particular, é essencial para a promoção real desses direitos. Assim, na medida em que se trata de mecanismo essencial para a realização dos comandos constitucionais sobre os direitos fundamentais, a existência de sistemas de monitoramento constitui um dever geral extraído da Constituição.

\section{Monitoramento das políticas públicas em Matéria de diReItos fUndamentais}

O monitoramento e a avaliação de políticas públicas, de forma ampla, pode ser levado a cabo sob diversas outras perspectivas - financeira, orçamentária, organizacional etc. —, aproximando-se de certo modo da avaliação do impacto legislativo (uma vez que a política tenha sido definida em lei) ${ }^{13}$. Naturalmente, nem toda política pública estará diretamente relacionada com a promoção imediata de direitos fundamentais: ainda assim, ela deverá ser objeto de monitoramento e avaliação ${ }^{14}$. No caso das políticas públicas em ma-

10 <https://www.redeitausocialdeavaliacao.org.br/wp-content/uploads/2015/11/relat_Mais_Educa\%C3\%A7\%C3\%A3o_ COMPLETO_20151118.pdf>. A pesquisa sobre a política pública em questão foi desenvolvida no âmbito de grupo de pesquisa do programa de pós-graduação da Faculdade de Direito da UERJ e conduzida de forma específica pelo doutorando Alessandro Molon. 11 <https://www.todospelaeducacao.org.br/biblioteca/1546/inaf---alfabetismo-no-mundo-do-trabalho/>.

12 CF/88: "Art. 205. A educação, direito de todos e dever do Estado e da família, será promovida e incentivada com a colaboração da sociedade, visando ao pleno desenvolvimento da pessoa, seu preparo para o exercício da cidadania e sua qualificação para o trabalho."

13 Sobre o tema, v. ANDRADE, Aparecida de Moura; SANTANA, Héctor Valverde. Avaliação de políticas públicas versus avaliação de impacto legislativo: uma visão dicotômica de um fenômeno singular. Revista Brasileira de Políticas Públicas, Brasília, v. 7, n. 3, p. 781-798, 2017.

14 Para um exemplo de monitoramento e avaliação dos resultados de política pública - no caso, de estímulo à pesquisa e desenvolvimento no âmbito do setor elétrico -, v. MUNHOZ, Igor Polezi; AKKARI, Alessandra Cristina Santos; SANTOS, Neusa Maria 
téria de direitos fundamentais, em particular, seu monitoramento também poderá se ocupar de diferentes dimensões ${ }^{15}$, mas, em qualquer caso, uma perspectiva indispensável a ser considerada será a que enfatiza a realização concreta dos direitos fundamentais que a política pretende promover, e é esse o enfoque que se pretende assumir neste trabalho.

Nesse contexto, o monitoramento envolve verificar se as metas que haviam sido estabelecidas quando da concepção da política estão sendo atingidas (caso, claro, elas tenham sido estabelecidas), acompanhar o que de fato está sendo executado no contexto da política em exame, e apurar os resultados concretos produzidos em face dos direitos fundamentais que se pretende promover, tendo em conta o problema que se pretendia solucionar por meio da política pública afinal ${ }^{16}$. De tal modo que, diante desse conjunto de dados, seja possível rever a política ou aspectos dela de modo a aprimorar sua capacidade de promover os resultados desejados. Esquematicamente, é possível falar, então, de sete etapas na dinâmica do monitoramento.

As duas primeiras etapas na dinâmica do monitoramento são prévias à execução das políticas públicas. Isso, porque, ao conceber uma política pública, os agentes públicos — sejam do Legislativo, do Executivo ou de qualquer outro órgão ou entidade estatal — devem, logicamente, valer-se de informação acerca de qual é o problema que a política pretende enfrentar e qual sua dimensão, bem como estabelecer quais as metas que se pretende atingir com a política proposta. Essas são duas questões bastante básicas, mas que podem ser bastante problemáticas e exigem enfrentamento ${ }^{17}$.

Conceber a política pública com base em informações acerca dos problemas e suas dimensões, para além de uma exigência lógica, é fundamental por ao menos duas razões jurídicas: a garantia da igualdade (art. $5^{\circ}$, caput) e a redução das desigualdades (art. $3^{\circ}$, III). Isso sem mencionar o debate da eficiência (art. 37, caput e art. 74, II), que não se enfrentará neste artigo em virtude da necessidade de limitar o escopo do estudo, e não por sua desimportância.

Em primeiro lugar, a informação é necessária para que seja possível dimensionar os recursos necessários para enfrentar o problema o que, possivelmente, repercutirá na própria concepção da política e nas decisões a serem tomadas. Imagine-se, em um exemplo esquemático, que o problema a ser enfrentado é o tratamento de câncer de mama no âmbito do SUS, e que existam 5 opções terapêuticas possíveis, de custo variado. Avaliar a quantidade estimada de pacientes que fará uso do tratamento nos anos subsequentes, por exemplo, será essencial para que se possa quantificar o custo global da política e assim fazer uma escolha que permita, ao menos tem tese, que todas as mulheres com a doença tenham acesso ao tratamento, e não apenas algumas delas.

Caso as decisões acerca de uma política pública não considerem informações sobre a dimensão do problema que ela pretende enfrentar, há um risco alto de violação da igualdade na fase da execução, já que a política não será capaz de atingir todos aqueles que deveriam ser por ela alcançados. Aparentemente, é o que acontece com parte importante das políticas de fornecimento gratuito de muitos medicamentos do SUS: as listas são generosas, como se viu acima, mas os medicamentos não estão disponíveis no sistema para boa parte da população que deveria recebê-lo, considerada a realidade epidemiológica do país.

Bastos Fernandes dos. Análise dos impactos diretos e indiretos do programa de P\&D da ANEEL no setor elétrico: diferenças com os EUA. Revista Brasileira de Politicas Públicas, v. 5, n. 2, p. 123-144, 2015.

15 A Portaria Interministerial no 102/2016, por exemplo, instituiu no âmbito do Poder Executivo Federal o Comitê de Monitoramento e Avaliação de Políticas Públicas Federais - CMAP cujos objetivos, nos termos de seu art. 1, são "I - aperfeiçoar políticas públicas, programas e ações do Poder Executivo federal para que alcancem melhores resultados; e II - aprimorar a alocação de recursos e melhorar a qualidade do gasto público". Ainda que o primeiro objetivo possa eventualmente abarcar múltiplas perspectivas, o segundo se concentra na gestão financeira das políticas públicas.

16 ORGANIZAÇÃO DAS NAÇÕES UNIDAS. Manual on human rights monitoring. Disponível em: <http://www.ohchr.org/EN/ PublicationsResources/Pages/MethodologicalMaterials.aspx>. Ver também, para uma discussão mais geral sobre o tema, sob a perspectiva da elaboração das normas e do controle de seus resultados, BARCELLOS, Ana Paula de. Direitos fundamentais e direito à justificativa: devido procedimento na elaboração normativa. Minas Gerais: Fórum, 2017.

17 ATIENZA, Manuel. Reasoning and legislation. In: WINTGENS, Luc J. (Org.). The theory and practice of legislation. Aldershot: Ashgate, 2005. p. 297-317. 
Adicionalmente, é provável que a política pública acabe por beneficiar sobretudo as camadas mais favorecidas da sociedade, que terão mais capacidade de influenciar os órgãos do Poder Executivo responsáveis pela execução da política — e, portanto, de obter prioridade no atendimento —, ou que tem maior facilidade de acesso ao Poder Judiciário, a fim de pleitear a adjudicação do que a política prometia, mas não foi entregue. Na realidade, como já se mencionou acima, como regra geral, sabe-se que as políticas públicas já beneficiam, primeiramente, os grupos mais privilegiados da sociedade, atingindo as camadas menos favorecidas apenas depois de algum tempo. É razoável supor que esse quadro se agrave, ainda, mais no caso de uma política que sequer considerou toda a demanda existente em sua concepção: o "depois" pode simplesmente não chegar, violando de forma ainda mais grave a isonomia.

A informação é relevante, também, para estabelecer prioridades caso não seja possível atender a todas as demandas existentes no âmbito de determinada política, tendo em conta que, nos termos constitucionais, a definição de prioridades deve ser orientada pela redução das desigualdades sociais (art. $3^{\circ}$, III). Ou seja: é preciso assegurar o atendimento das necessidades mais básicas para todos antes de avançar para níveis mais amplos de proteção, sob pena de ampliar ainda mais a desigualdade, ao invés de reduzi-la. Assim, por exemplo, localidades que têm educandos, mas não têm sequer escolas oferecendo educação infantil e fundamental, devem ser atendidas prioritariamente no âmbito das políticas públicas em matéria de educação. Já se pode perceber, como apontado acima, que também as informações acerca do problema devem ser regionalizadas e desagregadas em função de elementos que tradicionalmente indicam desigualdade no país, já que determinados grupos ou áreas podem ter realidades bastante diversas em comparação com outras.

Por fim, a informação acerca da realidade do problema que se pretende enfrentar será indispensável, também, para que se possa avaliar, ao longo da execução da política pública, se ela está produzindo algum impacto transformador sobre essa mesma realidade. Imagine-se uma política para estimular a leitura entre jovens e adolescentes. Se não há informação sobre a realidade antes da adoção da política, será difícil avaliar qual terá sido seu impacto (se algum) ao longo da execução da política.

Naturalmente, as informações existentes sobre os problemas - e mais ainda aquelas que procuram prever a evolução deles no futuro - são sempre limitadas e podem se mostrar imprecisas. Trata-se de uma limitação da própria capacidade humana e dos mecanismos de investigação existentes. Sob outra perspectiva, às vezes sequer há informação acerca da dimensão dos problemas a serem enfrentados — e, eventualmente, uma primeira fase da política pública pode envolver justamente a coleta de dados acerca da realidade. Seja como for, a limitação acerca do conhecimento sobre a realidade não justifica a defesa da ignorância, ou a acomodação com ela, pois as consequências dessa ignorância para a promoção efetiva dos direitos fundamentais podem ser dramáticas, e em geral em prejuízo daqueles que já são mais excluídos do acesso aos bens públicos.

Uma segunda etapa do monitoramento, para além da coleta/exame das informações sobre o problema, e também prévia à execução da política pública, envolve a fixação de metas a serem atingidas ao longo do tempo por essa política, metas que, naturalmente, possam ser observadas e avaliadas. Esse ponto pode apresentar algumas complexidades que não caberá ao Direito resolver, mas que ele precisa ao menos compreen$\operatorname{der}^{18}$. Em relação a alguns temas, a fixação de metas observáveis e mensuráveis é razoavelmente objetiva. Políticas envolvendo a ampliação da eletrificação ou das conexões de residências a uma rede de saneamento, por exemplo, podem ser medidas de forma numérica facilmente.

A questão já será mais complexa, por exemplo, em temas de saúde: embora o resultado final (outcome) seja a promoção, proteção e recuperação da saúde (art. 196), em geral é mais fácil estabelecer metas acerca das prestações efetivamente realizadas em relação a cada política específica, isto é: quantos procedimentos foram realizados, ou quantos exames, ou quantas consultas etc. (outputs). Há uma certa presunção relativa

18 GREEN, Maria. What we talk about when we talk about indicators: current approaches to human rights measurement. Human Rights Quarterly, v. 23, p. 1062-1097, 2001. 
de que mais exames, consultas, procedimentos e medicamentos contribuirão para a promoção, proteção e recuperação da saúde das pessoas, mas não é possível ter certeza de que há uma conexão necessária entre esses dois fenômenos sempre e para toda a população.

A complexidade aumenta ainda mais quando se trata do tema educação, por exemplo. Como medir se, após ser usuária dos serviços prestados pelo sistema educacional, a pessoa está preparada para exercer a cidadania, qualificada para o trabalho e plenamente desenvolvida, como pretende a Constituição (art. 205)? Será preciso conceber algum tipo de indicador, ou um proxy, que permita uma aproximação desse fenômeno. Em muitas partes do mundo, a performance dos estudantes em determinados testes padronizados, apesar de suas limitações, é o indicador mais comumente usado para esse fim. Há, porém, muitos debates acerca de qual seria a melhor forma de fazer essa avaliação e do que, afinal, significam pleno desenvolvimento da pessoa, qualificação para o trabalho e preparo para o exercício da cidadania

Um exemplo interessante de outra dimensão dessa complexidade pode ser observado na pesquisa realizada pelo IPEA sobre a Lei Maria da Penha, referida acima, e em sua discussão metodológica que, basicamente, pretendeu responder à seguinte pergunta: como medir e avaliar se a lei produziu resultados na redução da violência doméstica contra a mulher? É impossível saber quais seriam os níveis de violência caso a lei não existisse. O critério usado foi a comparação com os níveis de violência gerais observados da edição da lei, em 2006, até a realização do estudo, imaginando-se que o crescimento da violência doméstica entre as mulheres seria aproximadamente o mesmo: assim, eventual diferença relevante entre esses índices poderia ser razoavelmente imputada ao impacto da lei.

Em resumo: a fixação de metas para uma política pública pode, em si, ensejar uma série de discussões de natureza político-ideológica, além de debates mais técnicos de natureza metodológica, particularmente sob a perspectiva estatística. Esse ponto é importante, pois, embora a fixação de metas seja fundamental para a política pública em matéria de direitos fundamentais - para que seja possível avaliar ao longo do tempo se a política está ou não produzindo os resultados desejados —, ela nem sempre será singela. Essa circunstância, naturalmente, não significa que o tema deva ser deixado de lado, muito ao contrário. Se uma política pública não tem metas claras, observáveis e de alguma forma mensuráveis, simplesmente não será possível saber se o direito fundamental em questão está ou não sendo promovido, protegido ou respeitado. A realidade é complexa, mas é a realidade que o direito pretende transformar, de modo que não é possível fugir dessa complexidade.

Passando para as três próximas etapas lógicas do monitoramento, a doutrina que já existe sobre o tema identifica três grandes grupos de fenômenos que devem ser acompanhados, e sobre os quais se deverá ter informação desagregada ${ }^{19}$. O primeiro fenômeno a ser observado é denominado em geral pela expressão "inputs" e descreve os recursos financeiros, humanos ou de qualquer outra natureza investidos na política pública.

Nesse passo, uma primeira informação relevante a se apurar acerca de uma política públicas será o quanto se está investindo nela, bem como quantas pessoas e meios estão envolvidos na execução da tal política, e essa informação precisa ser desagregada ao menos territorialmente. A informação sobre os inputs não diz muito sobre o impacto efetivo da política na realidade dos direitos fundamentais que ela pretende promover. Nada obstante, tais dados serão importantes para vários tipos de controle relacionados com as despesas públicas. Por meio desses dados, já se pode saber, por exemplo, se as previsões orçamentárias estão sendo efetivamente executadas, se os investimentos mínimos previstos na Constituição, por exemplo, estão sendo dirigidos aos fins gerais previstos e, também, é possível identificar indícios de desvios e superfaturamento.

Além disso, sobretudo por conta da desagregação dos dados, as informações acerca dos inputs permitem avaliar que áreas estão recebendo mais ou menos recursos, e verificar se tais opções se justificam do

19 NORTON, Andy; ELSON, Diane. What's bebind the budget?: politics, rights and accountability in the budget process. London: ODI, 2002. 
ponto de vista constitucional e dos objetivos da própria política. Sobretudo após a edição da Lei de Acesso à Informação (Lei no 12.527/11), esse é o tipo de informação que se pode obter com mais facilidade na realidade brasileira hoje ${ }^{20}$. Mas dinheiro e recursos humanos, físicos ou tecnológicos também não significam automaticamente promoção de direitos fundamentais. É preciso prosseguir.

Um segundo conjunto de dados a ser monitorado é o que se identifica como outputs. Trata-se daquilo que efetivamente foi feito por conta da política: os serviços prestados, as atividades desenvolvidas, os bens fornecidos. A aplicação concreta dos inputs dará origem aos outputs. A informação acerca dos outputs também não revela ainda, realmente, o resultado da política sobre os direitos fundamentais, mas ao menos informa em que os inputs se materializaram concretamente. Uma coisa é saber que foram investidos x milhões de reais em determinada política; outra diversa é ter informação que descreva em que os tais x milhões de reais se transformaram em termos de serviços, produtos etc., e onde esses serviços e produtos foram ou estão sendo prestados ou fornecidos.

Na realidade, e como já referido, existe, apenas, uma presunção de que a realização dessas atividades e o fornecimento desses bens produzirá como resultado a promoção dos direitos fundamentais. Os outputs são atividades-meio: não há uma garantia de que eles conduzirão ao resultado desejado, a rigor, e daí a necessidade de se monitorar, também, os resultados efetivos (outcomes) sobre os direitos fundamentais. De todo modo, é realmente importante monitorar os outputs produzidos pelas políticas públicas de forma desagregada até porque, em geral, essa informação poderá ser mais facilmente coletada do que aquela relacionada com os outcomes.

Por fim, uma terceira informação a ser monitorada diz respeito ao impacto real da política pública sobre os direitos fundamentais: os outcomes. Como já se viu, dependendo do direito fundamental em exame e da política pública em discussão, o tema de como identificar e medir esse impacto será relevante. É importante, porém, perceber que a simples existência de informações sobre os inputs e outputs não é suficiente para avaliar se a política pública está, afinal, produzindo o resultado desejado em termos de direitos ${ }^{21}$. Como no exemplo do "Mais Educação" referido acima, ideias que pareciam ótimas podem não produzir o resultado que se antecipava, e é preciso aprofundar a investigação sobre elas e reavaliá-las (não necessariamente abandoná-las). Fingir que o resultado não é importante e que a simples existência de atividades-meio seria suficiente não produzirá, magicamente, por isso, a promoção, proteção e respeito aos direitos fundamentais.

As duas últimas etapas do monitoramento envolvem a avaliação dos dados produzidos sobre essas várias dimensões da realidade da política pública e sua eventual revisão. O objetivo do monitoramento não é punitivo. Não se trata de punir os responsáveis pela política que não atingiu as metas ou não promoveu os resultados pretendidos. Punições podem, eventualmente, ocorrer, se os dados revelarem práticas ilícitas, por evidente, mas não é esse o foco. O conhecimento e a previsibilidade humanas são falíveis e, mesmo quando

20 MANNARINO, Rosanne. Prestação de contas do governo da República para quem? a sociedade brasileira. In: SOUZA JUNIOR, José Geraldo de (Org.) Sociedade democrática, direito público e controle externo. Brasília: Universidade de Brasília, 2006. p. 229-240.; PEDERIVA, João Henrique. Accountability, constituição e contabilidade. Revista de Informação Legislativa, v. 35, n. 140, p. 17-39, 1998.; PONTES, João Batista; PEDERIVA, João Henrique. Contas prestadas pelo presidente da república: apreciação do Congresso Nacional. Brasília: Senado Federal, Consultoria Legislativa, 2004.

21 FRANCESCO, Fabrizio de.; RADAELLI, Claudio M.; TROEGER, Vera E. Implementing regulatory innovations in Europe: the case of impact assessment. Journal of European Public Policy, p. 1-21, 2011.; FLUECKIGER, Alexandre. Can better regulation be achieved by guiding parliaments and governments?: how the definition of the quality of legislation affects law improvement methods (concluding remarks). Legisprudence, v. 4, n. 2, p. 213-218, 2010.; ISSALYS, Pierre. Analyse d'impact et production normative: de l'efficacité à la légitimité. Revista da Faculdade de Direito da UFMG. n. Especial, p. 245-274, 2013.; MENEGUIM, Fernando B. Avaliação de impacto legislativo no Brasil. Berkeley Program in Law and Economics. Latin American and Caribbean Law and Economics Association (ALACDE) Annual Papers, 2010. Disponível em: <http://escholarship.org/uc/item/8ts831r2>.; RADAELLI, Cláudio M. The diffusion of regulatory impact analysis: best practice or lesson-drawing?. European Journal of Political Research, UK, v. 43 , n. 5, p. 723-747, 2004.; Radaelli, Claudio M. Quality of regulatory governance: impact assessment in comparative perspective. Full research report ESRC end of award report. RES-000-23-1284. Swindon: ESRC, 2009.; e SALINAS, Natasha Schmitt Caccia. Avaliação legislativa no Brasil: apontamentos para uma nova agenda de pesquisa sobre o modo de produção das leis. Revista Brasileira de Políticas Públicas, v. 10, n. 1, p. 228-249, 2013. 
implementadas como previsto, às vezes as normas não atingem os objetivos que pretendiam, ou não os atingem em todos os lugares ou relativamente a todos os grupos sociais ${ }^{22}$. Diante desses eventuais fracassos iniciais, é necessário repensar os meios pelos quais se pode tentar promover o fim inicialmente pretendido.

Isto é: mesmo que a política pública seja efetivamente executada, tal como concebida, não existe qualquer garantia de que a intervenção estatal na realidade produzirá os efeitos desejados sempre. Apenas o monitoramento dos resultados permitirá saber o que de fato está acontecendo, tendo em conta, repita-se, os vários grupos sociais e as várias regiões, já que a mesma política pode produzir efeitos diversos dependendo dos elementos com os quais venha a interagir na realidade ${ }^{23}$. A necessidade de avaliações e de revisões das políticas públicas é natural, mas ela somente poderá ocorrer diante do monitoramento efetivo dessas políticas em face do resultado concreto esperado em termos de direitos fundamentais.

\section{DeVER DE Monitoramento: LeVANDo OS DiReitos À SÉRIO E OUTRAS RAZÕES}

A última questão que cabe examinar pode ser formulada nos seguintes termos: o que o Direito Constitucional teria a ver com o tema do monitoramento das políticas públicas, apresentado sumariamente acima? Por que falar de um dever de monitoramento, no sentido jurídico-constitucional? Por quais razões o Direito Constitucional deveria se ocupar do assunto? O que se pretende demonstrar é que o tema é profundamente constitucional e deve ser objeto de reflexão e aprofundamento pelos estudiosos do Direito, justificando falar-se de um dever constitucional de monitoramento. As razões para isso seguem resumidas na sequência.

Em primeiro lugar, e como já enunciado, o compromisso constitucional com os direitos fundamentais tem uma dimensão de realidade, a saber: que as pessoas efetivamente tenham seus direitos garantidos, protegidos e promovidos no dia a dia. Ora, como se viu, as normas e as decisões judiciais sozinhas não têm o condão de transformar magicamente a realidade. Assim, é possível afirmar que o compromisso constitucional com os direitos fundamentais não é um compromisso propriamente com a existência de normas sobre o assunto, de políticas públicas de direitos fundamentais ou mesmo de decisões judiciais que determinem sua execução. Todos esses mecanismos serão meios para atingir um fim: a garantia efetiva, no dia a dia das pessoas, dos direitos fundamentais.

O percurso entre a norma e seu eventual impacto sobre a realidade não é indiferente para o Direito em geral, e para o Direito Constitucional em particular. Muito ao revés. E se, como se viu, o monitoramento das políticas públicas responsáveis pela promoção desses direitos é essencial para que esse impacto aconteça de fato, e da forma o mais equitativa possível, é natural que o tema deva ingressar na reflexão do Direito Constitucional. Para levar os direitos a sério, é preciso acompanhar, minimamente, o percurso da norma constitucional até a realização de seus propósitos na vida real.

Mas há uma segunda razão que justifica a importância de o Direito Constitucional se ocupar do tema do monitoramento das políticas públicas em matéria de direitos fundamentais. Se de um lado as políticas públicas destinam-se a promover direitos, de outro elas envolvem vultosos recursos públicos, recursos esses retirados da sociedade por meio, sobretudo, da tributação. Não há custo zero nessa dinâmica: nunca há, a rigor. A ação estatal é custeada pela sociedade que, portanto, tem menos recursos para si própria, de modo que as políticas públicas não produzem, apenas, benefícios: elas também restringem liberdades e direitos, na medida em que consomem recursos que poderiam ser alocados para outras finalidades, no âmbito da própria sociedade ou pelo próprio Estado.

22 SCOTT, James C. Seeing like a State: how certian schemes to improve the human condition have failed. New Haven: Yale University Press, 1998.

23 HOFFMANN, Rodolfo. Mensuração da desigualdade e da pobreza no Brasil. In: HENRIQUES, R. (Ed.). Desigualdade e pobreza no Brasil. Rio de Janeiro: IPEA, 2000. p. 81-107.; UNICEF. Social protection: accelerating the MDGs with equity. UNICEF, 2010. 
Retirar recursos da sociedade para a promoção de direitos fundamentais — sobretudo dos menos favorecidos - parece amplamente justificado, se, além do respeito aos limites constitucionais aplicáveis à intervenção do Estado sobre a propriedade, as políticas adotadas efetivamente estejam, tanto quanto possível, promovendo os direitos fundamentais que afirmam pretendem promover. Caso contrário, o Estado estará, apenas, desperdiçando os recursos da sociedade de forma irrazoável. Repita-se o que já se registrou acima: às vezes, a despeito de todo esse esforço de seriedade na elaboração de uma política pública, as coisas não se passarão como se antecipava. O conhecimento sobre o problema era mais limitado do que se supunha, os efeitos pretendidos não se produziram como imaginado e impactos não antecipados se mostraram extremamente graves, exigindo reformulações da política. Nada obstante, parece evidente que, sem monitoramento, a chance de sucesso será sempre mais remota. Ou seja: os fracassos até poderão acontecer como resultado das limitações cognitivas humanas, mas não como resultado de uma displicência institucional. O mínimo que se espera diante da centralidade dos direitos fundamentais e dos efeitos que as normas produzem sobre esses direitos é que toda a seriedade possível seja atribuída às políticas públicas que visam justamente a promover tais direitos.

Em terceiro lugar, o tema do monitoramento demanda atenção por parte do Direito Constitucional pois ele envolve de forma direta o exercício do Poder Político e limites a esse exercício sob uma dimensão contramajoritária: tema clássico do Direito Constitucional. Coletar informações sobre as políticas públicas informações desagregadas —, processá-las e colocá-las à disposição do público é uma atividade complexa, por vezes demorada e custosa, e provavelmente com pouco retorno eleitoral, já que ela pode demonstrar, por exemplo, que os resultados anunciados não foram alcançados. Por isso mesmo não seria contrafático assumir como premissa que o Poder Público preferiria, do ponto de vista político, gerar e divulgar apenas informações que revelem seus avanços e sucessos, ou ainda dados genéricos que não revelem quase nada.

Nada obstante, se o monitoramento e as informações por ele demandadas são fundamentais para a própria promoção dos direitos fundamentais - e sobretudo para a promoção dos direitos dos grupos menos favorecidos socialmente - , monitorar ou não os resultados das políticas públicas não pode ser uma opção livre a cargo dos agentes públicos encarregados dessas políticas. O monitoramento de uma política pública envolve muitas escolhas que exigem não apenas juízos técnicos, mas muitas vezes também políticos. Não se trata de o Direito pretender elaborar um sistema de monitoramento: trata-se, apenas, de impor o dever de que ele exista.

Por fim, em quarto lugar, o monitoramento dos resultados das políticas públicas é uma atividade indispensável para que exista informação acerca dessas políticas, de modo a permitir o debate público sobre elas: informações sobre quais as metas que se pretende alcançar com cada política, informações sobre os recursos investidos (inputs), as atividades desenvolvidas e bens fornecidos (outputs), e informações sobre os resultados efetivamente produzidos (outcomes) pelas políticas públicas ao longo do tempo, e considerando as diferentes regiões e grupos sociais. A garantia de respeito, proteção e a promoção de direitos é uma construção democrática que se desenvolve ao longo do tempo, e informação será sempre essencial nesse processo ${ }^{24}$.

Em uma democracia, além de um direito fundamental em si, o acesso à informação é indispensável para a promoção dos demais direitos, para além do papel. Se, em um república democrática, todos são iguais e responsáveis como cidadãos por deliberar e formular as escolhas coletivas — escolhas essas que vão afinal promover ou não os direitos de que as normas tratam —, o acesso à informação acerca de um tema tão fundamental quanto o da realidade de respeito ou desrespeito aos direitos fundamentais será indispensável para que essas escolhas possam ser feitas de forma minimamente consciente.

24 FREITAS, Juarez. O controle social do orçamento público. Revista Interesse Público, v. 11, p. 13-26, 2001.; MAINWARING, Scott.; WELNA, Christopher. Democratic accountability in Latin America. New York: Oxford University Press, 2003. 


\section{Considerações finais}

Passados 30 anos da Constituição de 1988, é possível afirmar que o discurso acerca da normatividade do texto constitucional e das normas de direitos fundamentais em particular tornou-se amplamente dominante, não apenas na doutrina como na jurisprudência. Também as últimas décadas assistiram a ampla produção normativa acerca da promoção dos mais diferentes direitos. A percepção, porém, é a de que, embora todos esses elementos sejam da maior importância, estão longe de serem suficientes para promover, no mundo real, os direitos das pessoas. É preciso aprofundar a reflexão sobre a estruturação das políticas públicas mecanismos que vão afinal conduzir o percurso das normas até sua efetiva realização —, sobre o monitoramento de seus resultados e sobre a geração e divulgação de informações acerca de todo esse processo.

Nesse sentido, cogitou-se neste artigo um dever jurídico-constitucional de monitoramento de políticas públicas e, também, se deixou claro que a elaboração e implantação de um sistema de monitoramento no âmbito de uma política pública é, em si, também, uma política pública que pode ser bastante complexa. Inicialmente, porém, se registrou, justamente, a dificuldade de execução de decisões judiciais que pretendem interferir em políticas públicas de forma ampla. A pergunta que se coloca é evidente: intervenções como as sugeridas acima não teriam o mesmo destino? A resposta é provavelmente afirmativa.

$\mathrm{Na}$ realidade, e como referido, também as decisões judiciais são apenas um ponto de partida, não de chegada, quando se trata de políticas públicas, no que se inclui a estruturação de sistemas de monitoramento. Inevitavelmente, as políticas públicas serão levadas a cabo por decisões do Legislativo e do Executivo, e os mecanismos de sanção de que o Direito dispõe dificilmente são capazes de compelir as instâncias majoritárias a agirem em determinado sentido caso elas não tenham interesse político de fazê-lo. Mas, então, qual o sentido de sustentar a existência de um dever jurídico-constitucional de monitoramento das políticas públicas? Nem tanto ao mar, nem tanto a terra, como diriam os antigos.

A despeito de suas prováveis limitações, as decisões judiciais podem ter um importante papel de desencadear o debate público e pautar a agenda política ${ }^{25}$, colocando em discussão temas que, sem as decisões judiciais, talvez não atrairiam a atenção da mídia, dos grupos sociais e do público em geral. Ainda que a decisão judicial não seja capaz de, sozinha, produzir o resultado pretendido, ela pode ajudar a desencadear o processo e, em conjunto com outros elementos, gerar estímulos para a construção dos meios necessários à proteção e promoção dos direitos. O Direito não pode tudo, e situar, adequadamente, nosso trabalho e suas potencialidades no contexto mais amplo no qual ele se insere, decorre da percepção de que a promoção dos direitos fundamentais é complexa e exige mais do que, apenas, normas ou decisões judiciais, e de que a sociedade é mais do que o Direito e o Direito é mais do que o Judiciário. O Direito não pode tudo, longe disso, mas ele continua a ter um papel importante a desempenhar e devemos fazê-lo da melhor forma possível.

\section{REFERENCIAS}

ANDRADE, Aparecida de Moura; SANTANA, Héctor Valverde. Avaliação de políticas públicas versus avaliação de impacto legislativo: uma visão dicotômica de um fenômeno singular. Revista Brasileira de Políticas Públicas, Brasília, v. 7, n. 3, p. 781-798, 2017.

ATIENZA, Manuel. Reasoning and legislation. In: WINTGENS, Luc J. (Org.). The theory and practice of legislation. Aldershot: Ashgate, 2005. p. 297-317.

BARCELLOS, Ana Paula de. Sanitation rights, public law litigation and inequality: a case study from Brazil.

25 BIRKLAND, T. Agenda setting in public policy. In: FISCHER, F.; MILLER, G.; SIDNEY, M. (Ed.). Handbook of public policy analysis: theory, politics and methods. New York: CRC Press, 2007. 
Health and Human Rights, v. 16, n. 2, p. 35-46, 2014.

BARCELLOS, Ana Paula de. Direitos fundamentais e direito à justificativa: devido procedimento na elaboração normativa. Minas Gerais: Fórum, 2017.

BILCHITZ. Poverty and fundamental rights. New York: Oxford University Press, 2007.

BIRKLAND, T. Agenda setting in public policy. In: FISCHER, F; MILLER, G.; SIDNEY, M. (Ed.). Handbook of public policy analysis: theory, politics and methods. New York: CRC Press, 2007.

BRASIL. Ministério da Saúde. Relação nacional de medicamentos essenciais: 2017. Disponível em: <http://bvsms. saude.gov.br/bvs/publicacoes/relacao_nacional_medicamentos_rename_2017.pdf>.

BRINKS, Daniel M.; GAURI, Varun. The law's majestic equality?: the distributive impact of judicializing social and economic rights. Perspectives on Politics, v. 12/2, p. 375-393, 2014.

BUGARIN, Maurício Soares; VIEIRA, Laércio Mendes; GARCIA, Leice Maria. Controle dos gastos públicos no Brasil: instituições oficiais, controle social e um mecanismo para ampliar o envolvimento da sociedade. Rio de Janeiro: Konrad-Adenauer-Stiftung, 2003. v. 32.

FLUECKIGER, Alexandre. Can better regulation be achieved by guiding parliaments and governments?: how the definition of the quality of legislation affects law improvement methods (concluding remarks). Legisprudence, v. 4, n. 2, p. 213-218, 2010.

FRANCESCO, Fabrizio de.; RADAELLI, Claudio M.; TROEGER, Vera E. Implementing regulatory innovations in Europe: the case of impact assessment. Journal of European Public Policy, p. 1-21, 2011.

FREITAS, Juarez. O controle social do orçamento público. Revista Interesse Público, v. 11, p. 13-26, 2001.

GARGARELLA, R.; DOMINGO, P.; ROUX, T. (Ed.). Courts and social transformation in new democracies: an institutional voice for the poor?. Aldershot/Burlington: Ashgate, 2006.

GAURI; BRINKS (Ed.). Courting social justice: judicial enforcement of social and economic rights in the developing world. Cambridge: Cambridge University Press, 2008.

GREEN, Maria. What we talk about when we talk about indicators: current approaches to human rights measurement. Human Rights Quarterly, v. 23, p. 1062-1097, 2001.

Hafner-Burton, Emilie M.; Tsutsui, Kiyoteru. Human rights in a globalizing world: the paradox of empty promises. American Journal of Sociology, v. 110/5, p. 1373-1411, 2005.

HOFFMANN, Rodolfo. Mensuração da desigualdade e da pobreza no Brasil. In: HENRIQUES, R. (Ed.). Desigualdade e pobreza no Brasil. Rio de Janeiro: IPEA, 2000. p. 81-107.

Human Rights Watch. World report. 2012. Disponível em: < https://www.hrw.org/sites/default/files/world_ report_download/wr2012.pdf>.

ISSALYS, Pierre. Analyse d'impact et production normative: de l'efficacité à la légitimité. Revista da Faculdade de Direito da UFMG. n. Especial, p. 245-274, 2013.

MAINWARING, Scott.; WELNA, Christopher. Democratic accountability in Latin America. New York: Oxford University Press, 2003.

MANNARINO, Rosanne. Prestação de contas do governo da República para quem? a sociedade brasileira. In: SOUZA JUNIOR, José Geraldo de (Org.) Sociedade democrática, direito público e controle externo. Brasília: Universidade de Brasília, 2006, p. 229-240.

MENEGUIM, Fernando B. Avaliação de impacto legislativo no Brasil. Berkeley Program in Law and Economics. Latin American and Caribbean Law and Economics Association (ALACDE) Annual Papers, 2010. Disponível em: <http://escholarship.org/uc/item/8ts831r2>. 
MUNDAY, Roderick. In the wake of 'good governance': impact assessments and the politicisation of statutory interpretation. Modern Law Review, v. 71/3, p. 385-412, 2008.

MUNHOZ, Igor Polezi; AKKARI, Alessandra Cristina Santos; SANTOS, Neusa Maria Bastos Fernandes dos. Análise dos impactos diretos e indiretos do programa de P\&D da ANEEL no setor elétrico: diferenças com os EUA. Revista Brasileira de Politicas Públicas, v. 5, n. 2, p. 123-144, 2015.

NORTON, Andy; ELSON, Diane. What's bebind the budget?: politics, rights and accountability in the budget process. London: ODI, 2002.

ORGANIZAÇÃO DAS NAÇÕES UNIDAS. Manual on human rights monitoring. Disponível em: < http:// www.ohchr.org/EN/PublicationsResources/Pages/MethodologicalMaterials.aspx>.

PEDERIVA, João Henrique. Accountability, constituição e contabilidade. Revista de Informação Legislativa, v. 35, n. 140, p. 17-39, 1998.

PONTES, João Batista; PEDERIVA, João Henrique. Contas prestadas pelo presidente da república: apreciação do Congresso Nacional. Brasília: Senado Federal, Consultoria Legislativa, 2004.

RADAELLI, Cláudio M. The diffusion of regulatory impact analysis: best practice or lesson-drawing?. European Journal of Political Research, UK, v. 43, n. 5, p. 723-747, 2004.

Radaelli, Claudio M. Quality of regulatory governance: impact assessment in comparative perspective. Full research report ESRC end of award report. RES-000-23-1284. Swindon: ESRC, 2009.

SALINAS, Natasha Schmitt Caccia. Avaliação legislativa no Brasil: apontamentos para uma nova agenda de pesquisa sobre o modo de produção das leis. Revista Brasileira de Políticas Públicas, v. 10, n. 1, p. 228-249, 2013.

SCOTT, James C. Seeing like a State: how certian schemes to improve the human condition have failed. New Haven: Yale University Press, 1998.

UNICEF. Social protection: accelerating the MDGs with equity. UNICEF, 2010.

VICTORA, Cesar G et al. Explaining trends in inequities: evidence from Brazilian child health studies. Lancet, v. 356, p. 1093-1098, 2000. 
Para publicar na revista Brasileira de Políticas Públicas, acesse o endereço eletrônico www.rbpp.uniceub.br

Observe as normas de publicação, para facilitar e agilizar o trabalho de edição. 